\title{
REVIEW \\ The developing landscape of diagnostic and prognostic biomarkers for spinal cord injury in cerebrospinal fluid and blood
}

\author{
CH Hulme ${ }^{1,2}$, SJ Brown ${ }^{1,2}$, HR Fuller ${ }^{1}$, J Riddell ${ }^{3}$, A Osman ${ }^{2}$, J Chowdhury ${ }^{2}$, N Kumar ${ }^{2}$, WE Johnson ${ }^{4}$ and \\ KT Wright ${ }^{1,2}$
}

Study design: Review study.

Objectives: The identification of prognostic biomarkers of spinal cord injury ( $\mathrm{SCl}$ ) will help to assign $\mathrm{SCl}$ patients to the correct treatment and rehabilitation regimes. Further, the detection of biomarkers that predict permanent neurological outcome would aid in appropriate recruitment of patients into clinical trials. The objective of this review is to evaluate the current state-of-play in this developing field.

Setting: Studies from multiple countries were included.

Methods: We have completed a comprehensive review of studies that have investigated prognostic biomarkers in either the blood or cerebrospinal fluid (CSF) of animals and humans following SCl.

Results: Targeted and unbiased approaches have identified several prognostic biomarkers in CSF and blood. These proteins associate with cellular damage following $\mathrm{SCl}$ and include components from neurons, oligodendrocytes and reactive astrocytes, that is, neurofilament proteins, glial fibrillary acidic protein, Tau and S100 calcium-binding protein $\beta$. Unbiased approaches have also identified microRNAs that are specific to $\mathrm{SCl}$, as well as other cell damage-associated proteins.

Conclusions: The discovery and validation of stable, specific, sensitive and reproducible biomarkers of SCI is a rapidly expanding field of research. So far, few studies have utilised unbiased approaches aimed at the discovery of biomarkers within the CSF or blood in this field; however, some targeted approaches have been successfully used. Several studies using various animal models and some with small human patient cohorts have begun to pinpoint biomarkers in the CSF and blood with putative prognostic value. An increased sample size will be required to validate these biomarkers in the heterogeneous clinical setting.

Spinal Cord (2017) 55, 114-125; doi:10.1038/sc.2016.174; published online 20 December 2016

\section{INTRODUCTION}

There is now a vast and expanding body of literature describing different novel approaches for the treatment of spinal cord injury (SCI). Despite this, actions to treat and rehabilitate following SCI have not changed. Outside of clinical trials, SCI is typically managed either by surgical stabilisation or conservative management in the acute and subacute setting, followed by physiotherapy in the subacute and chronic phases of injury. ${ }^{1,2}$ It is clear that the SCI research field as a whole is experiencing a significant delay in the translation of new interventions into the clinic. There are many valid reasons why scientists and clinicians alike are cautious to translate new therapies into humans, particularly as setting up appropriate clinical trials to demonstrate safety and efficacy can be difficult. ${ }^{3}$

There is a growing appreciation for the benefit of using biomarkers to help introduce new treatments and improve strategies of care for SCI patients. We suggest there are several ways (diagnostic, prognostic and therapeutic) in which measuring biomarkers in the blood or cerebrospinal fluid (CSF) might complement current clinical measures, such as the American Spinal Injuries Association (ASIA)
International Standards for Neurological Classification of Spinal Cord Injury (ISNCSCI) scoring system and assessment of dry biomarkers such as magnetic resonance imaging scans, to further the SCI field. Altogether, a panel of biomarkers and neurological tests perhaps even including electrophysiological assessments may provide clinicians with a much clearer picture as to an individuals' severity of neurologic impairment.

Predicting neurologic recovery based on the AIS grade assigned immediately following SCI is challenging. ${ }^{4,5}$ For patients, knowing whether they will regain the ability to walk, irrespective of neurological, bladder or bowel function improvement, remains their key concern. ${ }^{6}$ Identification of a panel of biomarkers that could accurately predict an individuals' ability to regain neurological, physical and autonomic function could be of great psychological benefit to these patients. Furthermore, depending on the individuals' prognosis, the treatment pathway could be tailored to ensure that optimal neurological and/or physical function is regained and that patient rehabilitative care is maintained until their best possible outcome is achieved.

${ }^{1}$ Institute of Science and Technology in Medicine (ISTM), Keele University, Keele, UK; ${ }^{2}$ Midland Centre for Spinal Injuries, RJAH Orthopaedic Hospital, Oswestry, UK; ${ }^{3}$ Institute of Neuroscience and Psychology, University of Glasgow, Glasgow, UK and ${ }^{4}$ Department of Biological Sciences, University of Chester, Chester, UK Correspondence: Dr KT Wright, Robert Jones and Agnes Hunt Orthopaedic Hospital, Oswestry SY10 7AG, UK.

E-mail: Karina.Wright@rjah.nhs.uk

Received 12 August 2016; revised 14 October 2016; accepted 31 October 2016; published online 20 December 2016 
ISNCSCI diagnosis of a SCI can be delayed because of problems associated with polytrauma stabilisation or a lack of SCI expertise at the treating hospital. Therefore, a diagnostic CSF or blood test that can be used to assess the neurological state of these individuals may provide a quicker, cheaper and more accurate method, which will empower clinicians to stratify patients to the most suitable treatments for their needs. In addition, as novel treatments to target the acute phase of SCI develop, quick and accurate diagnoses of patients who will be appropriate to recruit to these clinical trials will ensure studies are appropriately powered to assess efficacy. Despite prediction of neurological improvement having been the focus of a majority of biomarker studies, there is also value in the use of biomarkers to predict other long-term outcomes, such as neuropathic pain, for which early intervention studies could be implemented to try and prevent the onset of these conditions.

Currently, in both routine clinical care and in clinical trials, the neurological condition of individuals is assessed by ISNCSCI grading and imaging modalities. Biomarkers that can easily be repeatedly measured within the blood or CSF of these individuals to determine progressive neurological condition would be highly beneficial, as it would allow rapid determination as to whether the patient was improving, worsening or showed sustained neurological stability in response to their current treatment, thus providing a biological surrogate outcome measure. Further, such biomarkers might indicate whether the patient has increased neurological plasticity in response to a treatment or rehabilitation regime. Finally, biomarkers released into the CSF and/or blood may provide a plethora of information as to the patients' biological response to SCI. As discussed below, different biological responses to SCI may lead to specific molecules being released into the CSF or blood; these fluids may contain a unique fingerprint that can be used by scientists and clinicians to elucidate the mechanisms underlying an individual's SCI. Again, this could allow for personalised treatments to be provided to a patient that target their specific injury mechanisms and that can be used to assess their specific mechanistic responses.

In recent years, scientists have started to take up the challenge of discovering and validating biomarkers in the blood and CSF that have prognostic value in accurately diagnosing complete or incomplete SCI and determining SCI progression. This review aims to present an overview of the current state-of-play in this emerging field. We will explain how the biological process of SCI may lead to the release of biomarkers of interest into the CSF and blood; the techniques that are commonly used to find and validate these markers, and the preclinical and clinical studies that have already begun to highlight biomarkers of interest.

\section{SCI AND THE RELEASE OF BIOCHEMICAL BIOMARKERS}

This section of the review aims to highlight some of the major processes that occur following a SCI, which could lead to biomarker release. It is still unclear how biomarkers from the spinal cord are released into the blood following injury; however, we suggest that their release is likely to be highly influenced by the specific type of injury sustained and the biochemical properties of the biomarkers in question. The majority of biomarkers, which have already been studied in both pre-clinical and clinical studies, have been identified from targeted biomarker identification processes, that is, looking for markers that are likely released based on the known biological processes/mechanisms that occur following SCI.

\section{Spinal cord tissue damage}

In both animal models of SCI and in the human situation, spinal cord traumas fall broadly into two categories: transection injuries, where the spinal cord is penetrated with a sharp force; and the more common contusion traumas, where the spinal cord is essentially crushed., Both types of injury result in a breach of the blood-brain barrier (BBB) and either immediate primary or secondary damage to the neurons and glia of the spinal cord tracts. Rupture of these cell types results in the release of biomarkers, largely cellular components, which are specific in the indication of nervous tissue damage and include neurofilaments (NF), ${ }^{9}$ Tau, ${ }^{10}$ neuron-specific enolase (NSE), ${ }^{11}$ S100 calcium-binding protein $\beta(S 100 \beta)^{11}$ and glial fibrillary acidic protein (GFAP). ${ }^{9}$ These tissue-specific biomarkers (discussed in greater detail below) hold great promise as they are typically released into the CSF then taken up into the blood stream, allowing for their detection local to the injury site and systemically. The quantity of these proteins in the CSF and blood might directly relate to the extent of neuronal or glial damage that has occurred following SCI. ${ }^{12,13}$

\section{Inflammation}

In brief, the breakdown of the BBB allows for an influx of inflammatory cells into spinal cord tissues. Infiltrating leukocytes and resident microglia release proteolytic and oxidative enzymes, reactive oxygen species and an array of pro-inflammatory cytokines, including, for example, tumour necrosis factor-alpha (TNF- $\alpha){ }^{14,15}$ This spike in acute-phase pro-inflammatory molecules can be measured in human blood in the first $24 \mathrm{~h}$ following injury. ${ }^{16}$ Caution must be taken when considering the blood at this stage however, as many of the abundant proteins that are seen acutely after injury may be a result of the systemic response to trauma and not SCI per se; study of animal models where matched 'sham' injuries can be performed allows for the opportunity to establish which proteins are SCI specific. The pronounced acute pro-inflammatory response to injury induces a reactive process of secondary damage in the tissues that surround the original injury site, exacerbating neuronal damage and neurological dysfunction. ${ }^{14}$ This secondary damage cascade can continue for several weeks following SCI, contributing to an expanding matrix of proteins associated with neuronal and glial cell apoptosis, such as soluble CD95 ligand (sCD95L), an initiator of the Fas apoptotic pathway. ${ }^{17}$

\section{Glial scarring}

Glial cell activation and hypertrophy leads to the formation of a glial scar in the subacute and chronic phases of SCI. ${ }^{18}$ Astrocytes become reactive and synthesise an extracellular matrix, which is effective in restoring the $\mathrm{BBB}$, but that coincidentally inhibits axonal regrowth. ${ }^{18}$ The most potent of these astrocyte-associated nerve inhibitory molecules are the neural chondroitin sulphated proteoglycans (CSPGs). ${ }^{19,20}$ Myelin damage-associated molecules represent the other major nerve inhibitory molecules within the glial scar; these include myelin-associated glycoprotein (MAG), Nogo-A and oligodendrocytemyelin glycoprotein (OMgp). ${ }^{21}$ There is a vast body of literature that confirms that CSPGs, MAG, Nogo-A and OMgp can inhibit neurite outgrowth in vitro and axonal regrowth in vivo, ${ }^{22-28}$ and that treatments, which specifically target these molecules promote functional recovery in SCI pre-clinical studies both individually ${ }^{29,30}$ and in combination. ${ }^{31}$ However, there is little research exploring the utility of these molecules as prognostic biomarkers detectable in the $\mathrm{CSF}^{32}$ Perhaps this is because we associate such molecules with the subacute or chronic phases of injury, when a stable neurology is much more likely. However, biomarkers, such as CPSGs that could be used 
to monitor any transition from the subacute to chronic phase of injury might aid clinicians in decisions regarding rehabilitation.

\section{DETECTION OF BIOMARKERS FOR SCI USING UNBIASED APPROACHES}

Although it would be ideal, biomarkers of injury or disease are rarely either 'detectable' or 'undetectable'. In most cases, biomarkers vary in expression levels under different conditions. It is important, therefore, to have specific and sensitive methods to quantify these changes. Typically, immunoassays have been the method of choice for studies that aimed to evaluate SCI biomarkers within the blood or CSF. The enzyme-linked immunosorbent assay (ELISA) is the most commonly employed assay so far, and both homemade and commercial ELISA kits have been utilised. Automated immunoassay systems are available for some potential biomarkers, for example, the Liaison automatic analyser for S100 $\beta$ and NSE, ${ }^{9,33}$ but it seems unlikely that the use of automated systems will become widespread until such biomarkers have become fully validated for routine clinical use.

The vast majority of studies aimed at finding new biomarkers for SCI have been based on a hypothesis about a particular protein of interest. Shaw et al. ${ }^{34}$ for example, proposed that, due to their high abundance in neurons, detection of NF proteins in CSF and/or serum is highly likely to indicate neuronal damage. Of the three NF subunits (that is, light (L), medium (M) and heavy $(\mathrm{H})$ ), phosphorylated NF-H (pNF-H) was thought likely to be the most readily detectable in serum or CSF following neurological injury because of its relative resistance to protease degradation. ${ }^{34}$ The results from this hypothesis-driven study formed the basis of several further studies to evaluate the prognostic potential of this biomarker following SCI. ${ }^{9,35}$

Surprisingly very few studies, however, have employed higherthroughput techniques to identify new biomarkers of SCI. A search of PubMed using the terms 'proteomics AND spinal cord injury' and 'biomarkers AND spinal cord injury' identified just four publications in which the aim of the study was to identify new peripherally accessible biomarkers of SCI (Table 1). Even more surprisingly, given the popularity in other fields of biomedical research (recently reviewed by Crutchfield et al. ${ }^{36}$ ), only two of these studies reported the use of unbiased quantitative proteomic techniques to find novel biomarkers of SCI in the CSF or blood, whereas the remaining two studies employed relatively low-throughput array technology. Notwithstanding the limitations of array technology-based screening, several potential SCI biomarkers were identified in this way. Using a 34-cytokine sandwich ELISA microarray, Light et al. ${ }^{37}$ identified increased levels of matrix metalloproteinase- 8 protein in CSF samples taken from adult rats at 12 days post SCI, and Hachisuka et al. ${ }^{38}$ found increased serum levels of the microRNAs miR-9, miR-219 and miR-384-5 in mice at $12 \mathrm{~h}$ after contusion SCI $(n=8)$ compared with sham injury $(n=8)$ using a low-density microarray platform (Table 1).

Despite some findings using array technology-based screening, as expected, the unbiased quantitative proteomic comparisons were more fruitful in terms of the numbers of potential biomarkers that were identified. Using difference gel electrophoresis and mass spectrometry (MS) analysis to compare CSF from patients at 1-8 days post SCI, Sengupta et al. ${ }^{39}$ identified eight proteins that were differentially expressed between complete- and incomplete-injured patients (Table 1). Using a high-throughput label-free liquid chromatography-MS/MS quantitative proteomics technique, Lubienicka et al. ${ }^{40}$ compared CSF taken from rats at $24 \mathrm{~h}$ post SCI and identified 42 putative biomarkers, 10 of which are indicative of SCI severity (Table 1). Moghieb et al. ${ }^{41}$ also used MS to identify biomarkers of SCI; however, their approach was not to initially look for CSF or blood biomarkers; instead they assessed protein changes within spinal cord tissue segments, of which transferrin, triosephosphate isomerase 1, cathepsin D and phosphoprotein enriched in astrocytes 15 (PEA-15) were confirmed as altered in human SCI CSF.

Despite proteomics providing a popular platform for novel biomarker identification in many fields of study, other high-throughput techniques, such as lipidomics and metabolomics are also valuable in biomarker identification. ${ }^{36}$ As is the case with proteomics, only a limited number of published studies have utilised these approaches to elucidate biomarkers for SCI. Xu et al. ${ }^{42}$ demonstrated, by assessment of lipidomic analysis of polyunsaturated fatty-acid containing phosphatidylcholines within the spinal cord tissue, that spatiotemporal expression of one of these phosphatidylcholines matched with reactive microglia and astrocyte activity. Although not directly relevant to CSF or blood biomarkers, the study by Xu et al. indicates that the lipidomic analysis of these fluids may clarify the role of lipid metabolism and damage of the cell membrane following SCI. ${ }^{42}$ There is also a need to further study the metabolome of CSF and/or blood of SCI patients, as this represents the end-point of all gene, transcript and protein interactions. ${ }^{43}$ Peng et al. ${ }^{44}$ published a comprehensive paper highlighting that metabolomic analysis of plasma from SCI rats led to identification of a panel of metabolites that could be used to selectively determine injured compared with sham-injured animals, based on metabolite measurements alone. ${ }^{44}$ Analysis of these metabolites within the plasma of human SCI patients is required to see whether these findings translate to man, and further similar metabolomic studies of human blood samples may also pinpoint other biomarkers.

\section{IDENTIFYING BIOMARKERS IN THE CSF AND BLOOD OF PRE-CLINICAL MODELS AND HUMAN SCI PATIENTS USING 'TARGETED' APPROACHES}

As discussed previously, the vast majority of studies that aimed to assess CSF or blood biomarkers of SCI have done so based on 'targeted' proteins that are known to relate to the biological processes that occur following a SCI. Many of these biomarkers have so far been assessed in pre-clinical models of SCI. Pre-clinical models are highly controllable and provide the opportunity to measure differences in the concentration of a biomarker in animals with a SCI and sham-injured animals (a comparison not possible using human subjects). These models also allow for longitudinal analyses comparable to acute, subacute and chronic timeframes post SCI. It is, however, difficult to relate the phases of injury in rodent models to that of the human situation, particularly as much depends on which of the models of injury are used, and as such there is no published consensus of opinion.

Causes of human SCI are wide ranging; therefore, several different animal models have been generated in an attempt to account for this diversity, although it is extremely unlikely that any animal model will ever be able to replicate the complexity of human injury. As discussed previously, the two major categories of SCI are sharp force or 'stab' lesions and contusive injuries. In rodent models, contusion injuries are most commonly induced using blunt force impact devices, ${ }^{45}$ in which calibrated weights are dropped onto an impounder that is rested on the surgically exposed spinal cord. ${ }^{46,47}$ This technique allows for varying degrees of injury depending on the amount of force used. Other methods of inducing an injury include the use of an aneurysm clip or calibrated forceps to compress the cord for a set timeperiod. ${ }^{48,49}$ Contusion injuries are commonly used as models of incomplete injury, whereas to study complete injury, complete 
Table 1 Candidate blood and/or CSF biomarkers for $\mathrm{SCl}$ identified from high-throughput techniques

\begin{tabular}{|c|c|c|c|c|c|c|c|c|}
\hline Reference & Injury type & $\begin{array}{l}\text { Sample } \\
\text { numbers }\end{array}$ & Species & Sample & $\begin{array}{l}\text { Time of sampling } \\
\text { (after SCI) }\end{array}$ & Method of biomarker screening & \multicolumn{2}{|c|}{ Candidate biomarkers } \\
\hline Light et al. ${ }^{37}$ & $\begin{array}{l}\text { Contusion } \\
\text { Sham }\end{array}$ & $\begin{array}{l}n=4 \\
n=4\end{array}$ & Rat & CSF & 12 days & Cytokine ELISA microarray & \multicolumn{2}{|c|}{$\begin{array}{l}\text { Matrix } \\
\text { Metalloprotease- } 8 \\
\text { Thymus chemokine-1 }\end{array}$} \\
\hline $\begin{array}{l}\text { Hachisuka } \\
\text { et al. }{ }^{38}\end{array}$ & $\begin{array}{l}\text { Contusion (mild) } \\
\text { Contusion } \\
\text { (severe) } \\
\text { Sham } \\
\text { Untreated }\end{array}$ & $\begin{array}{l}n=8 \\
n=8 \\
n=8 \\
n=8\end{array}$ & Mouse & Serum & $12 \mathrm{~h}$ & Taq-man low-density array & \multicolumn{2}{|c|}{$\begin{array}{l}\text { miR-219 } \\
\text { miR-384-5p } \\
\text { miR-9 }\end{array}$} \\
\hline $\begin{array}{l}\text { Sengupta } \\
\text { et al. }{ }^{39}\end{array}$ & $\begin{array}{l}\text { Complete } \\
\text { Incomplete } \\
\text { Complete } \\
\text { Incomplete }\end{array}$ & $\begin{array}{l}n=7 \\
n=8 \\
n=3 \\
n=3\end{array}$ & Human & CSF & $\begin{array}{l}\text { 1-8 days (acute) } \\
15-60 \text { days } \\
\text { (subacute) }\end{array}$ & $\begin{array}{l}\text { Difference gel electrophoresis (DIGE) and } \\
\text { matrix-assisted laser desorption/ ionisation-mass } \\
\text { spectrometry (MALDI-MS) }\end{array}$ & $\begin{array}{l}\text { GTF3C5 } \\
\text { HP } \\
\text { IGHG2 } \\
\text { IGHG4 }\end{array}$ & $\begin{array}{l}\text { ALB } \\
\text { TF } \\
\text { AZGP1 } \\
\text { APOH }\end{array}$ \\
\hline $\begin{array}{l}\text { Lubienicka } \\
\text { et al. }{ }^{40}\end{array}$ & $\begin{array}{l}\text { Contusion } \\
\text { (moderate) } \\
\text { Contusion } \\
\text { (severe) } \\
\text { Sham }\end{array}$ & $\begin{array}{l}n=9 \\
n=9 \\
n=9\end{array}$ & Rat & CSF & $24 \mathrm{~h}$ & $\begin{array}{l}\text { Liquid chromatography-mass spectrometry } \\
\text { (LC-MS/MS) }\end{array}$ & $\begin{array}{l}\text { YWHAG } \\
\text { ORM1 } \\
\text { A1M } \\
\text { A2M } \\
\text { APOA1 } \\
\text { APOH } \\
\text { B2M } \\
\text { CA1 } \\
\text { CA2 } \\
\text { C3 } \\
\text { C1 } \\
\text { CRP } \\
\text { FAM3C } \\
\text { GPX3 } \\
\text { ITIH4 } \\
\text { ITIH3 } \\
\text { LASMP } \\
\text { F11R } \\
\text { KNG1 }\end{array}$ & $\begin{array}{l}\text { LDHA } \\
\text { IGKC } \\
\text { NBL1 } \\
\text { SCG5 } \\
\text { PRDX2 } \\
\text { PZP } \\
\text { ZMYND8 } \\
\text { S100A8 } \\
\text { F2 } \\
\text { SCG3 } \\
\text { SERPINC1 } \\
\text { CDH13 } \\
\text { MAP1 } \\
\text { YWHAZ }\end{array}$ \\
\hline
\end{tabular}

Abbreviations: CSF, cerebrospinal fluid; ELISA, enzyme-linked immonosorbant assay; SCI, spinal cord injury.

transection of the spinal cord is often carried out using either microscissors or a scalpel blade cutting all of the spinal cord tracts by surgical incision and under visual control using suction to visually check for a complete injury. ${ }^{50,51}$

Both human and pre-clinical models have been utilised to identify potential biomarkers of SCI progression. Tables 2 and 3 detail all of the studies (to our knowledge) that have assessed CSF and/or blood biomarkers of SCI in pre-clinical and human models, respectively. Here, we discuss the leading candidate biomarkers of SCI severity and prognosis identified thus far, based on their known relevance to the biological processes that result following SCI.

\section{NF proteins}

NF proteins are the most abundant proteins in the neuronal cytoskeleton. ${ }^{52}$ They interact with other cytoskeletal proteins to regulate axonal transport and neuronal signalling. ${ }^{52}$ The presence of extracellular NF proteins is an indication of axonal damage, and NF accumulation is seen in several neurological diseases ${ }^{53}$ including multiple sclerosis, ${ }^{54-56}$ amyotrophic lateral sclerosis ${ }^{54,57}$ and traumatic brain injury (TBI). ${ }^{58} \mathrm{NF}$ proteins have long half-lives (3 weeks and 2.5 months for NF-L and pNF-H, respectively), ${ }^{59,60}$ and $\mathrm{pNF}-\mathrm{H}$, in particular, is highly resistant to breakdown by calpain and other systemic $_{\text {proteases. }}{ }^{32}$ These proteins, therefore, provide attractive candidate biomarkers for SCI as they are not being broken down before detection would be possible. The phosphorylated form of NF-H $(\mathrm{pNF}-\mathrm{H})^{9,34}$ and NF-L $\mathrm{L}^{57,58}$ are the two subunits that have been most widely considered as biomarkers for SCI and shall be discussed in more detail below.

Neurofilament-heavy chain (NF-H). SCI has been shown to result in increased levels of pNF-H in the CSF and blood of humans, rats and canines, $9,34,61,62$ as assessed using ELISA. In rat serum, for example, no pNF-H can be detected, using ELISA, in uninjured and sham-injured animals; however, severe experimental SCI results in high levels of measurable pNF-H. ${ }^{34}$ A detailed study of serum pNF-H concentrations (again assessed using ELISA) in rats with contusion $(n=8)$ and spinal hemisection $(n=13)$ injuries resulted in biphasic pNF-H being detectable in the late acute, subacute and chronic phases of both injuries. ${ }^{34} \mathrm{~A}$ sharp peak in pNF-H was observed at $16 \mathrm{~h}$ post SCI, whereas maximal serum concentrations were seen at 3 days post SCI, returning to baseline levels at $\sim 18$ days. ${ }^{34}$

Animal studies have also revealed that blood pNF-H levels can indicate disease severity and directly relate to functional outcome. Nishida et al. ${ }^{62}$ demonstrated that in dogs with degenerative disc disease (DDD; $n=60)$, pNF-H levels rose incrementally with the grade of injury severity observed. This study also demonstrated that those animals with the highest serum pNF-H levels at veterinary presentation post SCI were not able to regain the ability to walk 


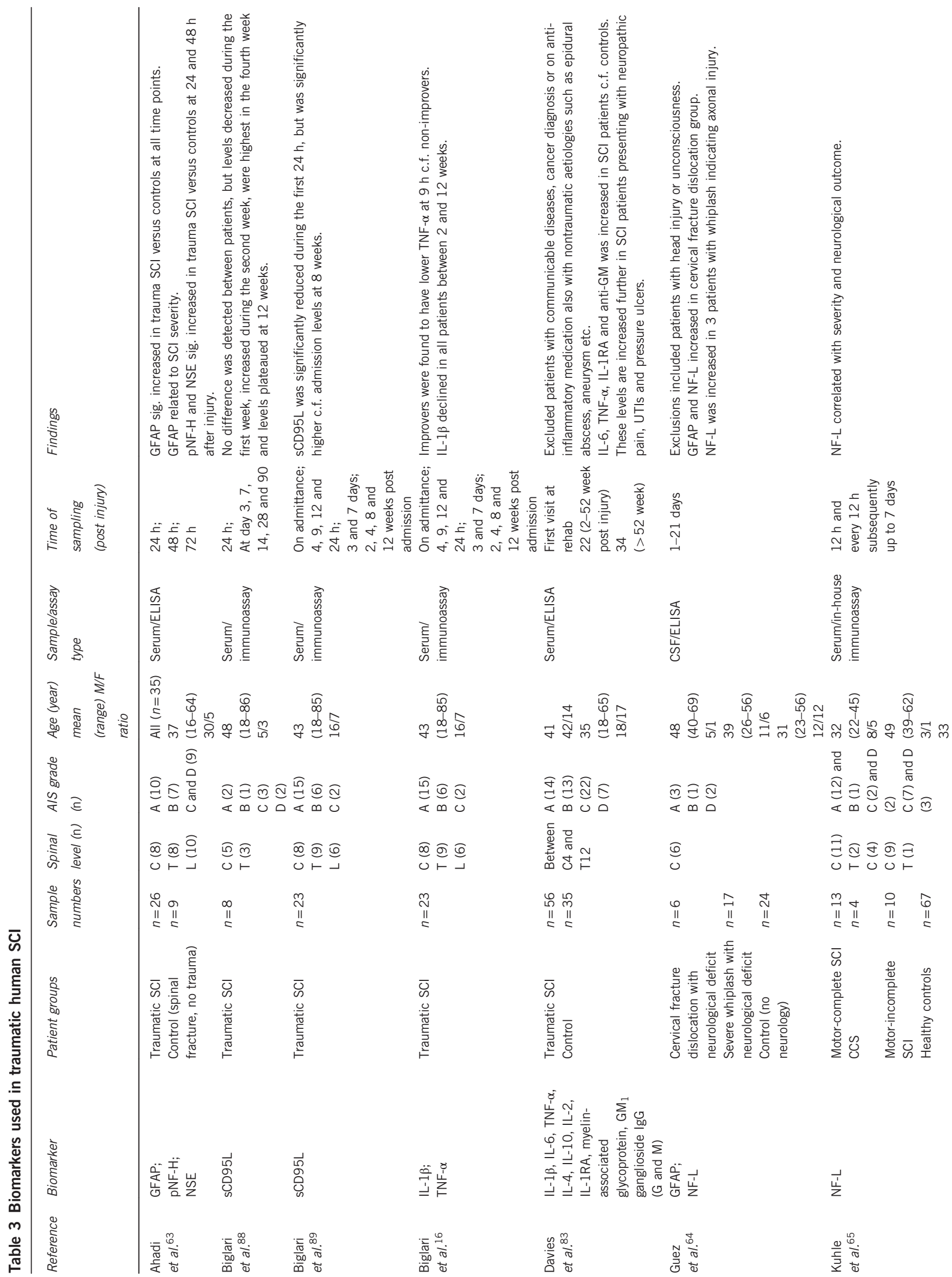




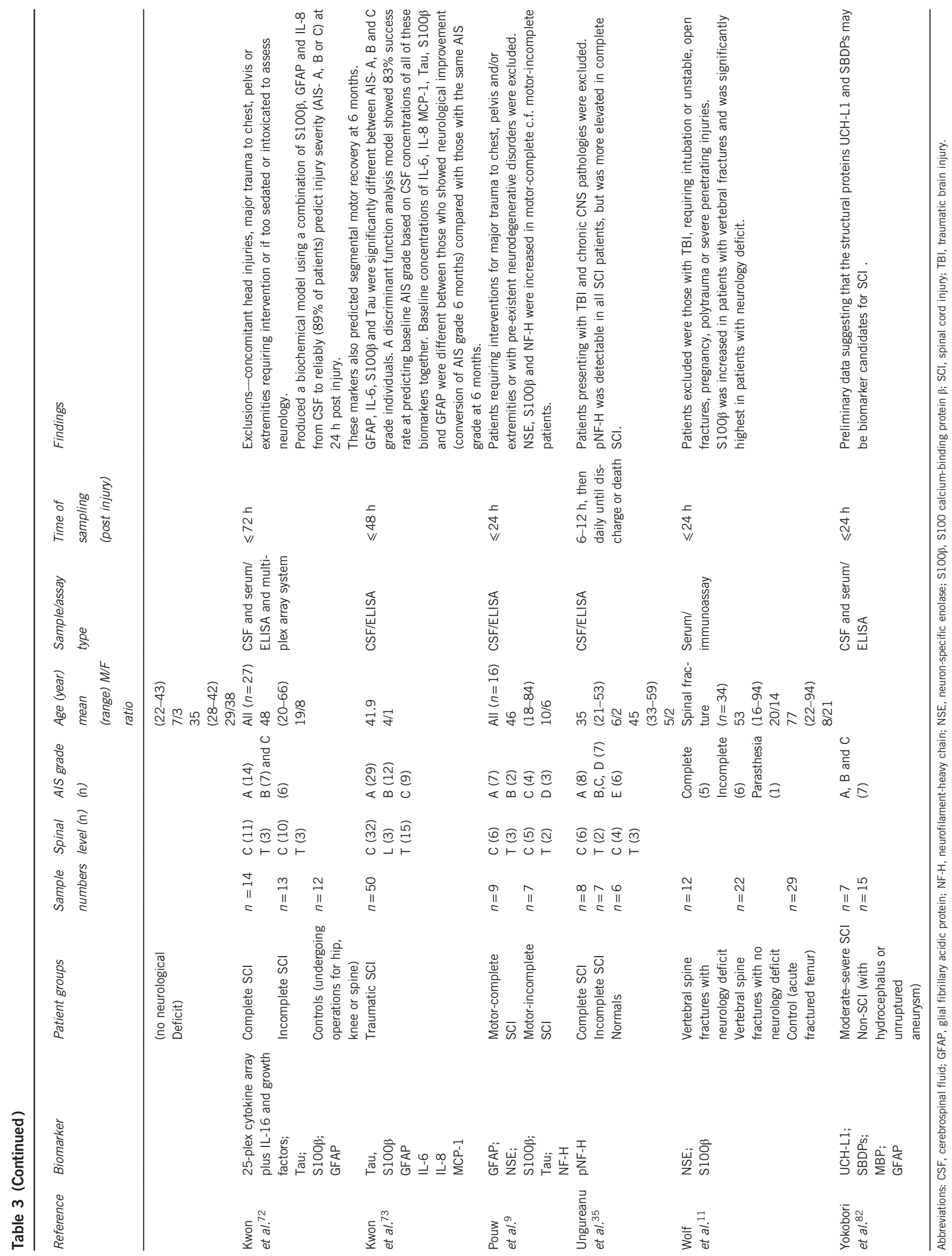


following surgery. ${ }^{62}$ Ueno et al. ${ }^{61}$ also demonstrated a negative correlation $(r=-0.78)$ between rat plasma pNF-H levels at 3 days post SCI and hindlimb function at 28 days post SCI (assessed using Basso, Beattie, Breshnahan score).

A small cohort of human studies also indicates that there is a correlation between pNF-H and disease state. In the CSF of SCI patients $(n=15)$, pNF-H concentrations are higher at $6-48 \mathrm{~h}$ post trauma compared with that in uninjured individuals $(n=6){ }^{35}$ Further, Pouw et al. ${ }^{9}$ found that NF-H concentrations in CSF were significantly greater in motor-complete $(n=9)$ patients compared with that in motor-incomplete patients $(n=7) .{ }^{9}$ In a recent slightly larger study, pNF-H levels in the serum of SCI trauma patients $(n=26)$ were significantly greater compared with that in controls with spinal fracture but no spinal cord trauma $(n=9)$ at 24 and $48 \mathrm{~h}$ post injury. ${ }^{63}$ These studies indicate that the measurement of pNF-H within the CSF and peripheral blood has potential as a prognostic biomarker in the acute phase of SCI.

Neurofilament-light chain (NF-L). Levels of NF-L have been assessed in both the CSF and serum of SCI patients. ${ }^{64,65}$ Guez et al. ${ }^{64}$ found there to be increased levels of NF-L in CSF following SCI compared with uninjured and whiplash-injured patients. ${ }^{64}$ This study also demonstrated that for a patient with complete injury and complete tetraparesis with no long-term neurological improvement, NF-L levels were 10-fold higher than that in a complete-injured patient who improved to AIS-D by 15 months post injury. ${ }^{64}$ This indicates that NF-L also may have utility as a biomarker of a patient's prognosis. In the later larger study, NF-L correlation with SCI severity and neurological outcome was confirmed. ${ }^{65}$ NF-L concentrations were found to be higher in the motor-complete $(n=13)$ patients $\left(70 \mathrm{pg} \mathrm{ml}^{-1}\right)$ and in motor-incomplete $(n=10)$ patients compared with others with central cord syndrome $\left(n=4 ; 6 \mathrm{pg} \mathrm{ml}^{-1}\right)$ and uninjured controls $\left(n=67 ; 5 \mathrm{pg} \mathrm{ml}^{-1}\right)$. Unlike pNF-H, the potential of NF-L as a biomarker for SCI has not been strengthened by preclinical studies. Despite this, NF-L is shown in preliminary human studies to have potential value in the classification of patients with or without capacity for neurological improvement.

\section{Tau}

Tau proteins are microtubule-stabilising proteins that are highly abundant in neurons. ${ }^{66-68}$ Like NFs, these proteins function to maintain axonal transport and neuronal transmission. ${ }^{69}$ Expression of Tau proteins within the CSF or blood of animals and humans is likely indicative of neuronal damage, as these proteins are not usually secreted. ${ }^{10}$ Although several investigations into the use of Tau as a biomarker for neurodegenerative diseases, such as conversion from mild cognitive impairment to Alzheimer's disease, ${ }^{70}$ have been described, there are fewer studies examining these proteins as putative biomarkers for SCI.

There are no publications of SCI research into Tau as a biomarker in typical laboratory animal models of SCI; however, veterinary studies looking to use Tau as a marker of SCI in dogs following IVD herniation (IVDH) suggest that an acute rise in Tau levels might indicate decreased capacity for functional recovery. ${ }^{71}$ In a study of 51 dogs, CSF was collected immediately on admission to the veterinary hospital. ${ }^{71}$ As Tau levels increase with injury severity (higher in incomplete-injured compared with healthy animals and in complete compared with incomplete-injured animals), the highest levels of CSF Tau protein corresponded with those dogs which took the longest time to recover function. ${ }^{71}$
In human studies, the consequence of SCI on Tau levels is not overly clear. Pouw et al. ${ }^{9}$ assessed Tau levels in CSF collected between 3 and $24 \mathrm{~h}$ post injury in motor-complete and motor-incomplete patients (with 7/16 patients having their CSF drawn before $15 \mathrm{~h}$ post injury) and found no significant differences associated with the degree of SCI. ${ }^{9}$ In contrast, two studies from Kwon et al. ${ }^{72,73}$ found that in CSF collected from complete or incomplete patients $24 \mathrm{~h}$ post injury, Tau concentrations were significantly elevated in a severity-dependent manner. ${ }^{72,73}$ This discrepancy between the studies could be because of a difference in patient numbers (Pouw et al., ${ }^{9} n=16$; Kwon et al. ${ }^{72}$ $n=27$; Kwon et al. ${ }^{73} n=50$ ) and possibly a difference in time between injury and CSF analysis. In combination with other markers, Tau can predict initial AIS grade and if its baseline measurement is low it can predict an improvement in AIS grade by 6 months post injury. ${ }^{73}$

Kwon et al. ${ }^{72}$ plotted Tau concentrations within the CSF from 8 to $120 \mathrm{~h}$ following a SCI. ${ }^{72}$ Interestingly, the concentration of Tau remained higher in AIS-A patients compared with AIS-B and AIS-C graded patients through to $48 \mathrm{~h}$ after injury; however, no difference in CSF concentrations of Tau existed between 48 and $120 \mathrm{~h}$ post injury. ${ }^{72}$ This observation highlights the dynamic nature of the biological processes that follow a SCI and the importance of assessing candidate biomarkers over time to ensure the most appropriate time is selected for measurement of differences in biomarkers.

\section{Neuron-specific enolase}

NSE is the dimeric neuronal form of the glycolytic enzyme enolase. This enzyme is a marker of ischaemic brain damage ${ }^{74}$ and although it only has a short biologic half-life $(\leqslant 24 \mathrm{~h}),{ }^{75}$ NSE holds promise as an acute indicator of neuronal damage.

NSE levels are elevated in the CSF, plasma ${ }^{76}$ and serum ${ }^{77}$ of rats in the acute phase of SCI. Further, NSE levels continue to be elevated at $24 \mathrm{~h}$ post injury in the serum of SCI compared with that of shaminjured rats; ${ }^{77}$ however, assessment in CSF or plasma for time-periods greater than $24 \mathrm{~h}$ post SCI has not been evaluated in rodent models. Again, in humans NSE has only been assessed in the acute period post injury ( $\leqslant 24 \mathrm{~h}),{ }^{9,11}$ and measurement outside of this timeframe may be inappropriate with respect to the short half-life of this protein.

Nonetheless, NSE has been shown to have potential as an indicator of SCI severity. In rats with mild $(n=20)$, moderate $(n=20)$ and severe $(n=20)$ spinal cord contusion injuries, $6 \mathrm{~h}$ measurements of CSF and plasma showed significantly greater levels of NSE in moderately and severely injured rats (with greater NSE levels in the severely versus moderately injured) compared with mildly injured animals. ${ }^{77}$ In humans, higher NSE concentrations were observed in the CSF of motor-complete patients $(n=9)$ compared with motorincomplete patients $(n=7) .9^{9}$ Results from Wolf et al., ${ }^{11}$ however, suggest that measurement of NSE in the serum of patients may be inappropriate to assess disease severity, as serum NSE concentrations within $24 \mathrm{~h}$ of injury were no different when patients with vertebral fractures with $(n=12)$ or without $(n=22)$ neurological deficit were compared. ${ }^{11}$

\section{S100 calcium-binding protein $\beta$ (S100ß)}

$\mathrm{S} 100 \beta$ is a glial-specific S100 protein that is released into blood and CSF during the acute phase of brain injury. ${ }^{78}$ S100 $\beta$ is involved in a diverse range of functions including calcium homoeostasis, enzyme activity and metabolism, cell proliferation and differentiation. ${ }^{79}$ Measurement of S100 $\beta$ has potential as an acute marker of SCI, as it is significantly increased in the blood ${ }^{76,77,80}$ and $\mathrm{CSF}^{76}$ of rats at $6 \mathrm{~h}$ after severe contusion injury when compared with sham injury. 
In the human acute setting ( $<48 \mathrm{~h}), S 100 \beta$ is also increased in the serum of patients with vertebral spine fractures (mean $=0.77 \mu \mathrm{g} \mathrm{l}^{-1}$; $n=34)$ compared with uninjured patients $\left(0.14 \mu \mathrm{gl}^{-1} ; n=29\right)^{11}$ and in the CSF of AIS-A grade patients compared with those with an AIS-B or C ISNCSCI score. ${ }^{73}$ Further, Pouw et al. ${ }^{9}$ showed there to be higher levels of detectable S100 $\beta$ in the CSF at $24 \mathrm{~h}$ in those patients who did not show improvement in AIS score at 6 or 12 months post injury. This finding is corroborated by Kwon et al. ${ }^{73}$ who showed decreased S100 $\beta$ concentrations within the CSF up to $48 \mathrm{~h}$ after injury in SCI patients who demonstrated an improvement in AIS grade by 6 months post injury. Therefore, early acute-phase assessment of S100 $\beta$ within the CSF could provide a predictive biomarker of neurological improvement.

Assessment of serum and CSF S100 $\beta$ concentrations outside of the acute setting has not yet been studied. However, results from animal studies demonstrate that by $24 \mathrm{~h}$ post injury, S100 $\beta$ levels are unaltered in response to $\mathrm{SCI},{ }^{77}$ perhaps limiting the potential of this biomarker for clinical use to the acute setting only. In addition, $S 100 \beta$ has been measured in conjunction with NSE in two animal studies, ${ }^{76,77}$ which indicated that co-measurement, rather than singular measurement of these markers in the acute stages of injury, is a more robust prognostic indicator of SCI severity.

\section{Glial fibrillary acidic protein}

The intermediate filament protein found in astroglia, GFAP, is a widely acknowledged biomarker of severe brain damage resulting from haemorrhage or serious trauma, with both serum and CSF levels being higher in patients with traumatic brain injury (TBI) compared with those in uninjured controls. ${ }^{81}$ Despite the fact that GFAP is an established marker of neural injury in other fields, very few studies have investigated its potential as a biomarker of SCI. In a small preliminary study, Yokobori et al. ${ }^{82}$ demonstrated higher GFAP levels in the CSF of rats in the acute phase following contusion injury $(n=4)$ compared with sham-injured animals $(n=4)$. Ahadi et al. ${ }^{63}$ demonstrated that GFAP is also increased in the serum of human acute SCI patients $(n=26)$ compared with uninjured controls $(n=9)$. Further, Pouw et al. ${ }^{9}$ and Kwon et al. ${ }^{73}$ confirmed that CSF GFAP concentrations were higher in complete versus incomplete SCI patients and hence that GFAP concentrations appear to be associated with SCI severity. ${ }^{9,73}$ Measurement of CSF GFAP within 48 h of injury has also been used, in combination with other inflammatory and structural markers, to predict which AIS-A patients would show an improvement in AIS score by 6 months post injury, with an $83 \%$ success rate. ${ }^{73}$ Therefore, acute assessment of CSF GFAP may provide a predictive biomarker of neurological improvement. Longitudinal analyses by Yokobori et al. ${ }^{82}$ showed maximal GFAP levels in CSF in rats at $4 \mathrm{~h}$ post SCI, with CSF concentrations decreasing sequentially at 24 and $48 \mathrm{~h}$ after injury; further studies are required to ascertain GFAP levels in the chronic phase of SCI.

\section{Pro-inflammatory cytokines}

Unsurprisingly, SCI can lead to the release of pro-inflammatory cytokines across the BBB. Therefore, several researchers have investigated whether concentrations of these cytokines in the blood of SCI patients relate to neurological outcome. TNF- $\alpha$ is a cytokine involved in the acute phase of pro-inflammatory signalling and is increased in the serum of SCI patients $(n=56)$ compared with that in uninjured controls $(n=35)$ in the subacute phase $(2-52$ weeks $){ }^{83}$ This pattern of increased serum TNF- $\alpha$ concentrations following SCI $(n=6)$ compared with sham injury is maintained in rats. ${ }^{84}$ Moreover, SCI patients who show improved neurological function had lower TNF- $\alpha$ at $9 \mathrm{~h}$ compared with SCI patients who failed to improve neurologically. ${ }^{16}$ Interleukin 1 beta (IL-1 $\beta$ ) is a key moderator of proliferation and inflammation that is thought to be vital for the formation of the glial scar. ${ }^{85}$ Ischaemia/ reperfusion SCI in rats $(n=6)$ resulted in increased serum IL- $1 \beta$ levels at both 24 and $48 \mathrm{~h}$ after injury when compared with that in sham-injured rats $(n=6) .{ }^{84}$ Despite human CSF or blood measurements of IL-1 $\beta$ not having been compared between SCI and uninjured individuals, baseline assessment ( $4 \mathrm{~h}$ after hospital admission) of this cytokine in serum showed no difference between patients who did or did not show an improvement in AIS score. ${ }^{16}$ Between weeks 1 and 4 after injury, however, serum IL- $1 \beta$ concentrations decreased significantly, only in patients who did not show an improvement in AIS score, ${ }^{16}$ indicating that maintenance of higher serum IL-1 $\beta$ concentrations may lead to improved neurological outcome. Previously, a pre-clinical model has also indicated that interleukin 6 (IL-6) may be a suitable blood biomarker to diagnose SCI, as at both 24 and $48 \mathrm{~h}$ after SCI serum concentrations of IL-6 were greater when compared with sham-injured rodents. ${ }^{84}$ More recently, Kwon et al. ${ }^{73}$ have demonstrated that CSF concentrations of pro-inflammatory cytokines, IL-6 and interleukin 8 (IL-8), can be assessed in the acute phase of human injury $(\leqslant 48 \mathrm{~h})$ to both determine injury severity and to predict neurological improvement from an AIS-A to either AIS-B or C grade by 6 months post injury.

\section{Soluble CD95 ligand (sCD95L)}

During the acute and subacute phase of SCI, neuronal damage via apoptosis is prolific. The Fas ligand receptor system is key in driving this apoptotic response. ${ }^{86}$ Soluble CD95 ligand (sCD95L/Fas-L) is a cleavage product of the type II transmembrane protein CD95L, ${ }^{17}$ which when activated and bound to CD95 (Fas) can initiate the Fas apoptotic pathway. sCD95L induces neutrophil secretion of proinflammatory chemokines. ${ }^{87}$ Although blocking the CD95 pathway in SCI rats improved functional outcome, assessment of human blood SCD95L via ELISA showed no difference in concentration when comparing complete versus incomplete-injured patients at $4 \mathrm{~h}$ and 12 weeks post injury. ${ }^{88,89}$ It is of note, however, that in these human studies no uninjured control group was included; as such it is difficult to determine whether $s \mathrm{CD} 95 \mathrm{~L}$ concentration alters at all in response to SCI.

\section{DISCUSSION}

This review has aimed to evaluate biomarkers in the CSF and/or blood that are currently under assessment as potential indicators of SCI diagnosis, severity and likely neurological outcome in pre-clinical and clinical studies. These studies have aimed to establish whether biomarker detection in CSF and blood is possible, to determine the longevity and stability of these biomarkers in each body fluid, and their value in predicting neurological outcome, as assessed by ISNCSCI score. All of the studies described are either in the preclinical stages of biomarker validation or have been undertaken only in a small number of human patients. Pre-clinical models provide an invaluable tool in which biomarker characteristics can be studied without the added complexity of clinical human-to-human SCI variability. Importantly, the use of sham-injured animals for comparison ensures that biomarkers that are specific to SCI are identified, as sham injury can account for systemic responses, such as systemic inflammation, that may occur in relation to the 'trauma' of sham injury. In human studies that have compared biomarkers between SCI and healthy 'controls', ${ }^{65}$ such healthy individuals are unlikely to demonstrate any of the systemic biological responses that may exist; therefore, some of the protein differences observed between the 
injured and control groups are likely to be non-specific to SCI. Access to appropriate human 'sham injury controls', where the same level and type of trauma is observed along with matched patient demographics but without any injury to the spinal cord tissue, is impossible to obtain. Guez et al., ${ }^{64}$ however, have assessed the utility of comparing SCI patients with individuals who had severe whiplash as a form of human 'sham'-injured control. The majority of candidate biomarkers in the described literature represent neural structural proteins that are likely to be damaged following SCI and released into the CSF and blood following disruption of the BBB. A cautionary aspect to consider for these SCI biomarkers is that some are known to increase in the CSF and blood of individuals with brain injury or nervous system disease, ${ }^{58,74,78,81}$ these confounding factors should be taken into consideration when exploring their utility in the clinic, especially in incidences of polytrauma. Further, some of the biomarkers that have indicated potential in SCI biomarker development have a short halflife (for example, NSE); therefore, accurate measurement of these may need to be carried out immediately after injury. Unfortunately, the assessment of SCI biomarkers in the acute setting $(<24 \mathrm{~h})$ might not always be possible, particularly in complex polytrauma cases where patient stabilisation is the priority.

Several of the studies included in this review have assessed biomarkers solely within the CSF. It is intuitive to think that body fluids local to the injury site will contain the highest concentration of SCI-specific molecules, metabolites or proteins. This has been confirmed by studies that have directly compared human biomarker concentrations in matched CSF and blood samples, which have demonstrated that acutely after injury $(\leqslant 48 \mathrm{~h})$ concentrations of IL-6, IL-8, MCP-1, Tau, S100 $\beta$ and GFAP were at least 10-fold higher in the CSF compared with that in the blood $;^{72}$ much higher CSF concentrations of biomarkers, including GFAP, were also demonstrated by Yokobori et al. ${ }^{82}$ The collection of CSF from SCI patients, however, increases their risk of infection of the meninges and has cost implications for the health service provider. ${ }^{90}$ Alternatively, if biomarkers can be identified systemically, the collection and analysis of peripheral blood would represent a less risky and more cost-effective approach. Therefore, there is benefit in pursuing techniques that are sensitive enough to detect differences in biomarker concentrations in blood; however, initial assessment of potential biomarkers may best be carried out in CSF where more apparent changes are likely to be noted.

The majority of published studies that have assessed blood or CSF biomarkers in human SCI patients have assessed the effectiveness of a biomarker based on its ability to predict or correspond to ISNCSCI score. However, it may be that other measures of progression, such as improvements in hand grasping, medical imaging or electrophysiology provide more subtle improvements, which could more easily be unpicked by a difference in biomarkers.

The use of unbiased approaches to screen for putative biomarkers of SCI progression in CSF and blood, for example quantitative proteomic approaches, have so far been largely overlooked, but are likely to yield the greatest number of novel biomarker targets. The limited proteomic analyses of CSF from SCI patients that exists provides a benchmark for the number of novel candidates that can be identified; ${ }^{41}$ however, there is currently a lack of any essential follow-on validation via quantitative western blot or ELISA. An alternative approach to identifying novel biomarkers using a high-throughput approach may be to assess protein changes within the spinal cord tissue and then evaluate whether these changes are reflected in the CSF or bloods, as could be demonstrated by Moghieb et al. ${ }^{41}$ Alternatively, as bioinformatic approaches aimed at interpreting large proteomic datasets improve, initial in silico validation of the candidate biomarkers might be possible as an interim step before completing costly quantitative validation; an approach, which has been effective in Alzheimer's disease. ${ }^{91}$

In this review, we have evaluated the current state-of-play in the CSF and/or blood biomarkers of SCI research landscape; this review highlights some of the potential pitfalls that need to be overcome to ensure the clinical utility of biomarker candidates, such as accounting for polytrauma and delayed SCI diagnoses. In addition, it is clear that further investigation is required, to include much larger cohorts of human participants with a diverse range of injuries to confirm the clinical validity of the preliminary biomarker findings described. The need to identify and validate novel prognostic biomarkers that can be measured within the blood or CSF, for the assessment of SCI progression using unbiased approaches has also been discussed.

It is highly unlikely that a single biomarker measurement will ever be used on its own to accurately predict SCI recovery in the clinic. We suggest that demographic and injury-associated risk factors as well as the evaluation of 'dry' biomarkers, that is, radiological imaging modalities and electrophysiological measurements in combination with the quantitation of several validated CSF and/or blood biomarkers will ultimately be used to provide a 'risk of SCI progression' index. Such a prognostic risk index would greatly advance the clinical management of SCI patients, reducing uncertainty for both patients and health-care providers in the acute SCI setting and providing confidence in neurological stability before the recruitment of SCI patients into clinical trials.

Finally, this review highlights the fact that very few studies have been published to identify biomarkers for other uses in the SCI field. Undoubtedly, biomarkers that could be used in clinical trials that aim to target specific disease mechanisms, such as remyelination, would be invaluable for assessing efficacy of a particular treatment and the mechanism of interest. Further, biomarkers that could be used to identify patients who will develop other long-term problems, such as neuropathic pain, would also be advantageous for the stratification of patients to particular treatment.

\section{CONFLICT OF INTEREST}

The authors declare no conflict of interest.

\section{ACKNOWLEDGEMENTS}

We would like to thank Professor Wagih El Masri for his expert professional opinion in this subject area and the support of the Midland Centre for Spinal Injuries patient fundraisers. This study was supported by the Midlands Centre for Spinal Injuries and the Institute of Orthopaedics, RJAH Orthopaedic Hospital, Oswestry, UK.

1 Medicine Consortium for Spinal Cord. Early acute management in adults with spinal cord injury: a clinical practice guideline for health-care providers. J Spinal Cord Med 2008; 31: 404-479.

2 Masri E. Management of traumatic spinal cord injuries: current standard of care revisited. Adv Clin Neurosci Rehabil 2010; 10: 37-40.

3 Tuszynski MH, Steeves JD, Fawcett JW, Lammertse D, Kalichman M, Rask C et al. Guidelines for the conduct of clinical trials for spinal cord injury as developed by the ICCP Panel: clinical trial inclusion/exclusion criteria and ethics. Spinal Cord 2007; 45: 222-231.

4 Fehlings MG, Vaccaro A, Wilson JR, Singh A, Cadotte DW, Harrop JS et al. Early versus delayed decompression for traumatic cervical spinal cord injury: results of the surgical timing in acute spinal cord injury study (STASCIS). PLOS ONE 2012; 7: e32037.

5 Fawcett JW, Curt A, Steeves JD, Coleman WP, Tusynski MH, Lammertse D et al. Guidelines for the conduct of clinical trials for spinal cord injury as developed by the ICCP panel: spontaneous recovery after spinal cord injury and statistical power needed for therapeutic clinical trials. Spinal Cord 2007; 45: 190-205. 
6 El Masri WS, Kumar N. Traumatic spinal cord injuries. Lancet 2011; 377: 972-974.

7 Bunge RP, Puckett WR, Becerra JL, Marcillo A, Quencer RM. Observations on the pathology of human spinal cord injury. A review and classification of 22 new cases with details from a case of chronic cord compression with extensive focal demyelination. Adv Neurol 1993; 59: 75-89.

8 Bunge RP, Puckett WR, Hiester ED. Observations on the pathology of several types of human spinal cord injury, with emphasis on the astrocyte response to penetrating injuries. Adv Neurol 1997; 72: 305-315.

9 Pouw MH, Kwon BK, Verbeek MM, Vos PE, van KA, Fisher CG et al. Structural biomarkers in the cerebrospinal fluid within $24 \mathrm{~h}$ after a traumatic spinal cord injury: a descriptive analysis of 16 subjects. Spinal Cord 2014; 52: 428-433.

10 Mori H, Hosoda K, Matsubara E, Nakamoto T, Furiya Y, Endoh R et al. Tau in cerebrospinal fluids: establishment of the sandwich ELISA with antibody specific to the repeat sequence of tau. Neurosci Lett 1995; 186: 181-183.

11 Wolf $\mathrm{H}$, Krall C, Pajenda G, Leitgeb J, Bukaty AJ, Hajdu S et al. Alterations of the biomarker S-100B and NSE in patients with acute vertebral spine fractures. Spine J 2014; 14: 2918-2922.

12 Zetterberg $\mathrm{H}$, Smith DH, Blennow K. Biomarkers of mild traumatic brain injury in cerebrospinal fluid and blood. Nat Rev Neurol 2013; 9: 201-210.

13 Csuka E, Morganti-Kossmann MC, Lenzlinger PM, Joller H, Trentz O, Kossmann T. IL-10 levels in cerebrospinal fluid and serum of patients with severe traumatic brain injury: Relationship to IL-6, TNF-alpha, TGF-beta1 and blood-brain barrier function. J Neuroimmunol 1999; 101: 211-221.

14 Carlson SL, Parrish ME, Springer JE, Doty K, Dossett L. Acute inflammatory response in spinal cord following impact injury. Exp Neurol 1998; 151: 77-88.

15 Trivedi A, Olivas AD, Noble-Haeusslein LJ. Inflammation and spinal cord injury: Infiltrating leukocytes as determinants of injury and repair processes. Clin Neurosci Res 2006; 6: 283-292.

16 Biglari B, Swing T, Child C, Buchler A, Westhausser F, Bruckner T et al. A pilot study on temporal changes in IL- $1 \beta$ and TNF- $\alpha$ serum levels after spinal cord injury: the serum level of TNF- $\alpha$ in acute $\mathrm{SCl}$ patients as a possible marker for neurological remission. Spinal Cord 2015; 53: 510-514.

17 Janssen O, Qian J, Linkermann A, Kabelitz D. CD95 ligand-death factor and costimulatory molecule? Cell Death Differ 2003; 10: 1215-1225.

18 Silver J, Miller JH. Regeneration beyond the glial scar. Nat Rev Neurosci 2004; 5: $146-156$

19 Cole GJ, McCabe CF. Identification of a developmentally regulated keratan sulfate proteoglycan that inhibits cell adhesion and neurite outgrowth. Neuron 1991; 7: 1007-1018.

20 Katoh-Semba R, Matsuda M, Kato K, Oohira A. Chondroitin sulphate proteoglycans in the rat brain: candidates for axon barriers of sensory neurons and the possible modification by laminin of their actions. Eur J Neurosci 1995; 7: 613-621.

21 Kastin AJ, Pan W. Targeting neurite growth inhibitors to induce CNS regeneration. Curr Pharm Des 2005; 11: 1247-1253.

22 McKerracher L, David S, Jackson DL, Kottis V, Dunn RJ, Braun PE. Identification of myelin-associated glycoprotein as a major myelin-derived inhibitor of neurite growth. Neuron 1994; 13: 805-811.

23 Chen MS, Huber AB, van der Haar ME, Frank M, Schnell L, Spillmann AA et al. Nogo-A is a myelinassociated neurite outgrowth inhibitor and an antigen for monoclonal antibody IN-1. Nature 2000; 403: 434-439.

24 Fournier AE, GrandPre T, Strittmatter SM. Identification of a receptor mediating Nogo-66 inhibition of axonal regeneration. Nature 2001; 409: 341-346.

25 Wang KC, Koprivica V, Kim JA, Sivasankaran R, Guo Y, Neve RL et al. Oligodendrocytemyelin glycoprotein is a Nogo receptor ligand that inhibits neurite outgrowth. Nature 2002; 417: 941-944.

26 Oertle T, van der Haar ME, Bandtlow CE, Robeva A, Burfeind P, Buss A et al. Nogo-A inhibits neurite outgrowth and cell spreading with three discrete regions. J Neurosci 2003; 23: 5393-5406.

27 Wright KT, Masri WEI, Osman A, Roberts S, Chamberlain G, Ashton BA et al. Bone marrow stromal cells stimulate neurite outgrowth over neural proteoglycans (CSPG), myelin associated glycoprotein and Nogo-A. Biochem Biophys Res Commun 2007; 354: 559-566.

28 Wright KT, Uchida K, Bara JJ, Roberts S, Masri WEI, Johnson WEB. Spinal motor neurite outgrowth over glial scar inhibitors is enhanced by coculture with bone marrow stromal cells. Spine J 2014; 14: 1722-1733.

29 Bradbury EJ, Moon LDF, Popat RJ, King VR, Bennett GS, Patel PN et al. Chondroitinase $A B C$ promotes functional recovery after spinal cord injury. Nature 2002; 416: 636-640.

30 Freund P, Wannier T, Schmidlin E, Bloch J, Mir A, Schwab ME et al. Anti-Nogo-A antibody treatment enhances sprouting of corticospinal axons rostral to a unilateral cervical spinal cord lesion in adult macaque monkey. J Comp Neurol 2007; 502: 644-659.

31 Zhao RR, Andrews MR, Wang D, Warren P, Gullo M, Schnell L et al. Combination treatment with anti-Nogo-A and chondroitinase $A B C$ is more effective than single treatments at enhancing functional recovery after spinal cord injury. Eur J Neurosci 2013; 38: 2946-2961.

32 Hayes KC, Hull TCL, Delaney GA, Potter PJ, Sequeira KAJ, Campbell K et al. Elevated serum titers of proinflammatory cytokines and CNS autoantibodies in patients with chronic spinal cord injury. J Neurotrauma 2002; 19: 753-761.

33 Marquardt G, Setzer M, Theisen A, Tews D-S, Seifert V. Experimental subacute spinal cord compression: correlation of serial S100B and NSE serum measurements, histopathological changes, and outcome. Neurol Res 2011; 33: 421-426.
34 Shaw G, Yang C, Ellis R, Anderson K, Mickle JP, Scheff S et al. Hyperphosphorylated neurofilament NF-H is a serum biomarker of axonal injury. Biochem Biophys Res Commun 2005; 336: 1268-1277.

35 Ungureanu D, Dimitriu C, lencean AS, Tascu A. Determination of the phosphorylated neurofilament subunit NF-H (pNF-H) in cerebro-spinal fluid as biomarker in acute traumatic spinal cord injuries. Rev Rom Med Lab 2014; 22: 377-387.

36 Crutchfield CA, Thomas SN, Sokoll LJ, Chan DW. Advances in mass spectrometry-based clinical biomarker discovery. Clin Proteomics 2016; 13: 1.

37 Light M, Minor KH, DeWitt P, Jasper KH, Davies SJ. Multiplex array proteomics detects increased MMP-8 in CSF after spinal cord injury. J Neuroinflammation 2012; 9: 122.

38 Hachisuka S, Kamei N, Ujigo S, Miyaki S, Yasunaga Y, Ochi M. Circulating microRNAs as biomarkers for evaluating the severity of acute spinal cord injury. Spinal Cord 2014; 52: $596-600$.

39 Sengupta MB, Basu M, Iswarari S, Mukhopadhyay KK, Sardar KP, Acharyya B et al. CSF proteomics of secondary phase spinal cord injury in human subjects: perturbed molecular pathways post injury. PLOS ONE 2014; 9: e110885.

40 Lubieniecka JM, Streijger F, Lee JHT, Stoynov N, Liu J, Mottus R et al. Biomarkers for severity of spinal cord injury in the cerebrospinal fluid of rats. PLOS ONE 2011; 6: e19247.

41 Moghieb A, Bramlett H, Das J, Yang Z, Selig T, Yost R et al. Differential neuroproteomic and systems biology analysis of spinal cord injury. Mol Cell Proteomics 2016; 15: 2379-2395.

42 Xu D, Omura T, Masaki N, Arima H, Banno T, Okamoto A et al. Increased arachidonic acid-containing phosphatidylcholine is associated with reactive microglia and astrocytes in the spinal cord after peripheral nerve injury. Sci Rep 2016; 6: 26427.

43 Dunn WB. Mass spectrometry in systems biology an introduction. Methods Enzymol 2011; 500: 15-35.

44 Peng J, Zeng J, Cai B, Yang H, Cohen M, Chen W et al. Establishment of quantitative severity evaluation model for spinal cord injury by metabolomic fingerprinting. PLoS ONE 2014; 9: 93736.

45 Vijayaprakash KM, Sridharan N. An experimental spinal cord injury rat model using customized impact device: a cost-effective approach. J Pharmacol Pharmacother 2013; 4: 211-213.

46 Koozekanani SH, Vise WM, Hashemi RM, McGhee RB. Possible mechanisms for observed pathophysiological variability in experimental spinal cord injury by the method of Allen. J Neurosurg 1976; 44: 429-434.

47 Zhang N, Fang M, Chen H, Gou F, Ding M. Evaluation of spinal cord injury animal models. Neural Regen Res 2014; 9: 2008-2012.

48 Gruner JA, Yee AK, Blight AR. Histological and functional evaluation of experimental spinal cord injury: evidence of a stepwise response to graded compression. Brain Res 1996; 729: 90-101.

49 Onifer SM, Rabchevsky AG, Scheff SW. Rat models of traumatic spinal cord injury to assess motor recovery. ILAR J 2007; 48: 385-395.

50 Xu XM, Chen A, Guénard V, Kleitman N, Bunge MB. Bridging Schwann cell transplants promote axonal regeneration from both the rostral and caudal stumps of transected adult rat spinal cord. J Neurocytol 1997; 26: 1-16.

51 Fouad K, Schnell L, Bunge MB, Schwab ME, Liebscher T, Pearse DD. Combining schwann cell bridges and olfactory-ensheathing glia grafts with chondroitinase promotes locomotor recovery after complete transection of the spinal cord. J Neurosci 2005; 25: 1169-1178.

52 Miller CCJ, Ackerley S, Brownlees J, Grierson AJ, Jacobsen NJO, Thornhill P. Axonal transport of neurofilaments in normal and disease states. Cell Mol Life Sci 2002; 59: 323-330.

53 Al-Chalabi A, Miller CCJ. Neurofilaments and neurological disease. BioEssays 2003; 25: 346-355.

54 Gaiottino J, Norgren N, Dobson R, Topping J, Nissim A, Malaspina A et al. Increased neurofilament light chain blood levels in neurodegenerative neurological diseases. PLoS ONE 2013; 8: 9.

55 Kuhle J, Malmestrom C, Axelsson M, Plattner K, Yaldizli O, Derfuss T et al. Neurofilament light and heavy subunits compared as therapeutic biomarkers in multiple sclerosis. Acta Neurol Scand 2013; 128: e33-e36.

56 Trentini A, Comabella M, Tinotore M, Koel-Simmelink MJ, Killestein J, Roos B et al. $\mathrm{N}$-acetylaspartate and neurofilaments as biomarkers of axonal damage in patients with progressive forms of multiple sclerosis. J Neurol 2014; 261: 2338-2343.

57 Weydt P, Oeckl P, Huss A, Müller K, Volk AE, Kuhle J et al. Neurofilament levels as biomarkers in asymptomatic and symptomatic familial amyotrophic lateral sclerosis. Ann Neurol 2016; 79: 152-158.

58 Cai JY, Lu C, Chen MH, Ba HJ, Chen XD, Lin JH et al. Predictive value of phosphorylated axonal neurofilament subunit $\mathrm{H}$ for clinical outcome in patients with acute intracerebral hemorrhage. Clin Chim Acta 2013; 424: 182-186.

59 Millecamps S, Gowing G, Corti O, Mallet J, Julien JP. Conditional NF-L transgene expression in mice for in vivo analysis of turnover and transport rate of neurofilaments. J Neurosci 2007: 27: 4947-4956.

60 Yuan A, Sasaki T, Rao MV, Kumar A, Kanumuri V, Dunlop DS et al. Neurofilaments form a highly stable stationary cytoskeleton after reaching a critical level in axons. J Neurosci 2009; 29: 11316-11329.

61 Ueno T, Ohori Y, Ito J, Hoshikawa S, Yamamoto S, Nakamura K et al. Hyperphosphorylated neurofilament NF-H as a biomarker of the efficacy of minocycline therapy for spinal cord injury. Spinal Cord 2011; 49: 333-336.

62 Nishida H, Nakayama M, Tanaka H, Kamishina H, Izawa T, Hatoya S et al. Evaluation of serum phosphorylated neurofilament subunit NF-H as a prognostic biomarker in dogs with thoracolumbar intervertebral disc herniation. Vet Surg 2014; 43: 289-293. 
63 Ahadi R, Khodagholi F, Daneshi A, Vafaei A, Mafi AA, Jorjani M. Diagnostic value of serum levels of GFAP, pNF-H, and NSE compared with clinical findings in severity assessment of human traumatic spinal cord injury. Spine 2015; 40: E823-E830.

64 Guéz M, Hildingsson C, Rosengren L, Karlsson K, Toolanen G. Nervous tissue damage markers in cerebrospinal fluid after cervical spine injuries and whiplash trauma. J Neurotrauma 2003; 20: 853-858.

65 Kuhle J, Gaiottino J, Leppert D, Petzold A, Bestwick JP, Malaspina A et al. Serum neurofilament light chain is a biomarker of human spinal cord injury severity and outcome. J Neurol Neurosurg Psychiatry 2015; 86: 273-279.

66 Brandt R, Lee G. The balance between tau protein's microtubule growth and nucleation activities: implications for the formation of axonal microtubules. J Neurochem 1993; 61: 997-1005.

67 Wang JZ, Liu F. Microtubule-associated protein tau in development, degeneration and protection of neurons. Prog Neurobiol 2008; 85: 148-175.

68 Weingarten MD, Lockwood AH, Hwo SY, Kirschner MW. A protein factor essential for microtubule assembly. Proc Natl Acad Sci USA 1975; 72: 1858-1862.

69 Drubin DG, Kirschner MW. Tau protein function in living cells. J Cell Biol 1986; 103 : 2739-2746.

70 Blennow KB. CSF biomarkers for mild cognitive impairment. J Intern Med 2004; 256 224-234.

71 Roerig A, Carlson R, Tipold A, Stein VM. Cerebrospinal fluid tau protein as a biomarker for severity of spinal cord injury in dogs with intervertebral disc herniation. Vet J 2013; 197: 253-258.

72 Kwon BK, Stammers AMT, Belanger LM, Bernardo A, Chan D, Bishop CM et al. Cerebrospinal fluid inflammatory cytokines and biomarkers of injury severity in acute human spinal cord injury. J Neurotrauma 2010; 27: 669-682.

73 Kwon BK, Streijger F, Fallah N, Noonan VK, Belanger LM, Ritchie L et al. Cerebrospinal fluid biomarkers to stratify injury severity and predict outcome in human traumatic spinal cord injury. J Neurotrauma 2016; 33: 1-14.

74 Rech TH, Vieira SR, Nagel F, Brauner JS, Scalco R. Serum neuron-specific enolase as early predictor of outcome after in-hospital cardiac arrest: a cohort study. Crit Care 2006; 10: R133.

75 Tiainen M, Roine RO, Pettilä V, Takkunen O. Serum neuron-specific enolase and S-100B protein in cardiac arrest patients treated with hypothermia. Stroke 2003; 34 2881-2886

76 Cao F, Yang X, Liu W, Hu W, Li G, Zheng X et al. Elevation of neuron-specific enolase and S-100beta protein level in experimental acute spinal cord injury. J Clin NeurosCi 2008; 15: 541-544.

77 Loy DN, Sroufe AE, Pelt JL, Burke DA, Cao QL, Talbott JF et al. Serum biomarkers for experimental acute spinal cord injury: rapid elevation of neuron-specific enolase and S-100beta. Neurosurgery 2005; 56: 391-397.
78 Marchi N, Rasmussen P, Kapural M, Fazio V, Kight K, Mayberg MR et al. Peripheral markers of brain damage and blood-brain barrier dysfunction. Restor Neurol Neurosci 2003; 21: 109-121.

79 Donato R, Sorci G, Riuzzi F, Arcuri C, Bianchi R, Brozzi F et al. S100B's double life: Intracellular regulator and extracellular signal. Biochim Biophys Acta 2009; 1793: 1008-1022.

80 Ma J, Novikov LN, Karlsson K, Kellerth JO, Wiberg M. Plexus avulsion and spinal cord injury increase the serum concentration of S-100 protein: an experimental study in rats. Scand J Plast Reconstr Surg Hand Surg 2001; 35: 355-359.

81 Diaz-Arrastia R, Wang KKW, Papa L, Sorani MD, Yue JK, Puccio AM et al. Acute biomarkers of traumatic brain injury: relationship between plasma levels of ubiquitin C-terminal hydrolase-L1 and glial fibrillary acidic protein. J Neurotrauma 2014; 31: 19-25.

82 Yokobori S, Zhang Z, Moghieb A, Mondello S, Gajavelli S, Dietrich WD et al. Acute diagnostic biomarkers for spinal cord injury: review of the literature and preliminary research report. World Neurosurg 2015; 83: 867-878.

83 Davies AL, Hayes KC, Dekaban GA. Clinical correlates of elevated serum concentrations of cytokines and autoantibodies in patients with spinal cord injury. Arch Phys Med Rehabil 2007; 88: 1384-1393.

84 Hasturk A, Atalay B, Calisaneller T, Ozdemir O, Oruckaptan H, Altinors N. Analysis of serum pro-inflammatory cytokine levels after rat spinal cord ischemia/ reperfusion injury and correlation with tissue damage. Turk Neurosurg 2009; 19: 353-359.

85 Wang CX. Olschowka JA, Wrathall JR. Increase of interleukin-1 beta mRNA and protein in the spinal cord following experimental traumatic injury in the rat. Brain Res 1997; 759: 190-196.

86 Zhang $N$, Yin $Y, X u$ SJ, Wu YP, Chen WS. Inflammation \& apoptosis in spinal cord injury. Indian J Med Res 2012; 135: 287-296.

87 Shudo K, Kinoshita K, Imamura R, Fan H, Hasumoto K, Tanaka M et al. The membrane-bound but not soluble form of human Fas ligand is responsible for its inflammatory activity. Eur J Immunol 2001; 31: 2504-2511.

88 Biglari B, Buchler A, Swing T, Biehl E, Roth HJ, Bruckner T et al. Increase in soluble CD95L during subacute phases after human spinal cord injury: a potential therapeutic target. Spinal Cord 2013; 51: 183-187.

89 Biglari B, Buchler A, Swing T, Child C, Biehl E, Reitzel T et al. Serum SCD95L concentration in patients with spinal cord injury. J Int Med Res 2015; 43: 250-256.

90 Eng RH, Seligman SJ. Lumbar puncture-induced meningitis. JAMA 1981; 245: 1456-1459.

91 Greco I, Day N, Riddoch-Contreras J, Reed J, Soininen H, Kłoszewska I et al. Alzheimer's disease biomarker discovery using in silico literature mining and clinical validation. J Trans/ Med 2012; 10: 217. 